\title{
A 2-year-old male child with diffuse abdominal pain, mass in the abdomen and red currant jelly stool
}

\author{
Md. Golam Hafiz, Chowdhury Yakub Jamal, Md. Anwarul Karim, Afiqul Islam, \\ Md. Iqbal Hossain, A. K. M. Nurul Kabir and Md. Tosaddeque Hossain Siddiqui
}

\begin{abstract}
Article Info
Department of Pediatric Hematology and Oncology, Faculty of Pediatrics,

Bangabandhu Sheikh Mujib Medical University, Shahbag, Dhaka, Bangladesh (MGH, CYJ, MAK, Al); Department of Radiology and Imaging, Faculty of Medicine, Bangabandhu Sheikh Mujib Medical University, Shahbag, Dhaka, Bangladesh (MIH); Department of Pathology, Faculty of Basic Science and Paraclinica Science, Bangabandhu Sheikh Mujib Medical University, Shahbag, Dhaka Bangladesh (AKMNK); Department of Pediatric Surgery, Faculty of Surgery, Bangabandhu Sheikh Mujib Medical University, Shahbag, Dhaka, Bangladesh (MTHS)

For Correspondence:

Md. Golam Hafiz

golamhafiz59@yahoo.com

Received:

Accepted:

Available Online:

22 February 2019 10 March 2019

15 March 2019

ISSN: 2224-7750 (Online)

2074-2908 (Print)

DOI: 10.3329/bsmmuj.v12i1.40453
\end{abstract}

Keywords: Abdominal pain; HenochSchonlein purpura; intussusceptions; Mass; Non-Hodgkin's lymphoma; Stool

\section{Cite this article:}

Hafiz MG, Jamal CY, Karim MA, Islam A Hossain MI, Kabir AKMN, Siddiqui MTH.

A 2-year-old male child with diffuse abdominal pain, mass in the abdomen and red currant jelly stool. Bangabandhu Sheikh Mujib Med Univ J. 2019; 12: 60-68.

\section{Copyright:}

The copyright of this article is retained by the author(s) [Atribution CC-By 4.0]

Available at:

www.banglajol.info

\section{Presentation of Case}

Dr. Md. Golam Hafiz (Associate Professor): A 2year-old male child, the second issue of nonconsanguineous parents, from average socioeconomic status hailing from Dinajpur, Bangladesh was attended at Pediatric Surgery outpatient department with the complaints of vague diffuse abdominal pain in the lower right side of abdomen and around the umbilical region for last 3 days. His mother also reported the feeling of a solid mass in the abdomen during dressing of her child. Then, gradually his problems were increasing in nature with several times of nausea, vomiting, and the passage of blood mixed stool three times before his admission.

Dr. Md. Tosaddeque Hossain Siddiqui (Professor): On admission, the child was found with a tender, distended abdomen and the signs and symptoms of peritonitis. On query, the child was found immunized as per the expanded program of immunization schedule of Bangladesh and had no history of contact with a tuberculous patient prior to his illness. He was found with increased bowel sounds movement on auscultation. Per rectal examination of the child showed red currant jelly stool and was found with balloon-like swelling of the rectum

Dr. Md. Saiful Islam Bulbul (Associate Professor): Complete blood count report of the child showed total leukocyte counts $\left(25 \times 10^{9} / \mathrm{L}\right)$ with neutrophilia, i.e., neutrophilic leukocytosis $(90 \%)$. The erythrocyte sedimentation rate was within normal limit. The liver and renal function tests of the child were found within the normal limit.

Dr. Md. Iqbal Hossain (Professor): The chest X-ray of the child showed no radiological ab -normalities. The plain X-ray radiograph of the abdomen showed dilated intestinal loops with a significant number of levels of air fluid (Figure 1A).

The abdominal ultrasonogram was done using warm gel and $10 \mathrm{MHz}$ linear transducer at the right quadrant of abdomen. Gradually the transducer moved proximally towards the right upper abdomen aligning the transducer in the transverse direction to the colon which revealed the presence of palpable pseudokidney mass and was consistent with intussusceptions of the bowel at the right lumbar region. The intussusception extend to the epigastric region with the involvement of lymph nodes of the mesentery of small intestine (Figure 1B).

When the child viewed axially, there showed a hypo echoic ring from the edematous walls of the intussuscipiens around an echo-dense center which was formed by interfaces of the mucosal and serosal layers of intussusceptum; the characteristic sign called "target sign" or "Doughnut sign"(Figure1C)

Dr. Hossain: The ultrasound findings of the abdomen showed ileoileocolic intussuscep-

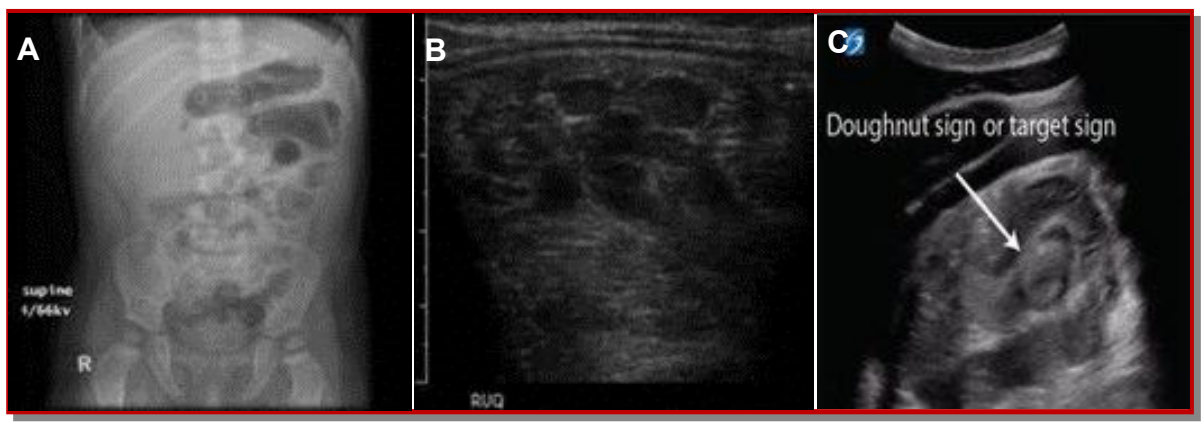

Figure 1: Plain $\mathrm{X}$ - ray radiograph of abdomen showing dilated intestinal loops with air fluid level (A); ultrasonogram of abdomen representing intussusceptions of small intestine (B); ultrasonogram of abdomen showing doughnut sign, the characteristic of intussusceptions (C) 

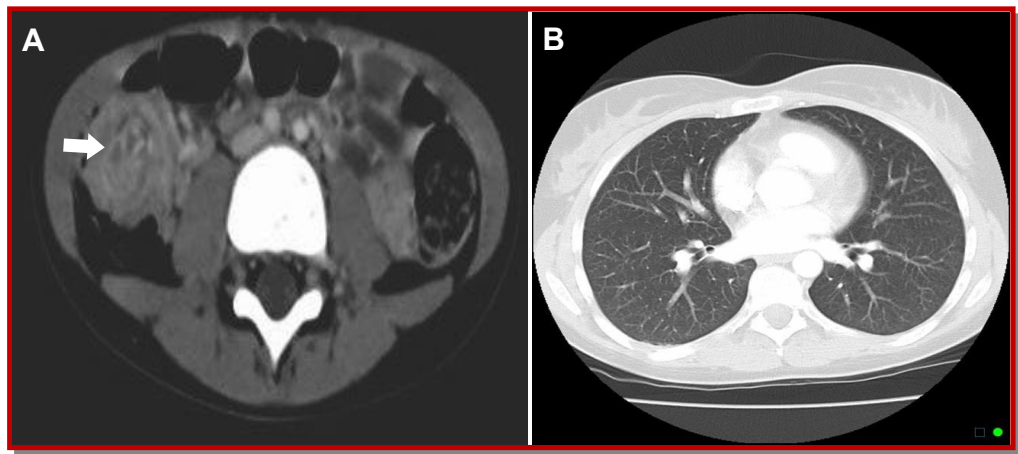

Figure 2: Photomicrograph on admission showing the cut section of CT scan of the abdomen and pelvis with contrast resembling whorled appearance (alternate hypo and isodense, marked by a white arrow) and air-fluid levels located in the inferior side of the abdominal cavity (A); CT scan of the chest showing no mediastinal lymph node involvement (B)

tions at the right lumbar region which extended to the epigastric region and was asso-ciated with the involvement of surrounding lymph node of the mesentery. The computed tomography scan of whole abdomen and pelvis with contrast showed a rounded mass with whorled appearance (alternate hypo and iso-dense) heterogenous area measuring $3.5 \times 3.5 \mathrm{~cm}$, with an ill-defined contour in the right flank of the abdomen resembling doughnut (marked by a white line). The appearance was

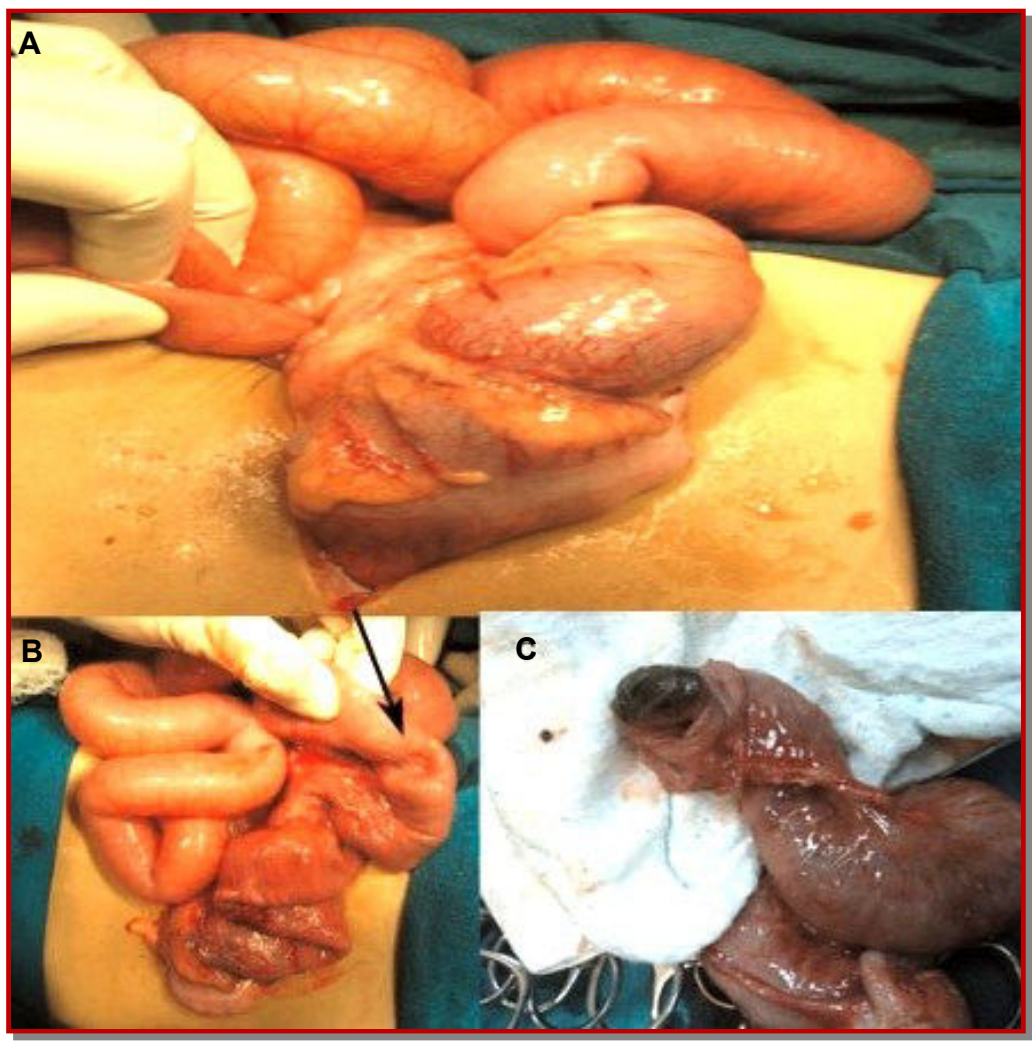

Figure 3: Photograph representing the ileoileocolic intussusceptions (A); thickened external layer (area) as seen from the outside (B); cut section of intussusceptions showing the sessile polyp (C) similar to that of a false kidney mass or a bag sign and found to be attached to the right colon. The small intestinal loops were hugely dilated with thickening of their walls. A few air-fluid levels were located on the inferior side of the abdominal cavity (Figure 2A). The computed tomography scan of the chest was found with no mediastinal lymph node involvement (Figure 2B). Then, the child was immediately transferred to the operation theater for emergency operation.

\section{Per-operative Findings}

Dr. Siddiqui: The laparotomy of the child was performed successfully and per-operative observations were confirmed the child as ileoileocolic intussusceptions with a small $(2.25 \times$ $2.25 \mathrm{~cm}$ ) submucosal sessile like polyp (Figure 3A). The consistency of this intussuscep-tions was firm in the distal ileum as the point of the lead having a thickened external layer as seen from outside (Figure 3B). There were some mild to moderate congestion and hemorrhage found in mucosal area of the intussusceptions of sessile polyp (Figure 3C).

In the operative field, the lymph nodes of the mesentery were found to be enlarged in size and shape. Then, hemicolectomy was performed and the tissue sample was sent to the Pathology Department for histopathological examination. The child was, then, transferred to the post-operative ward and kept under regular follow-up of the vital signs which were well maintained by the attending physicians and nursing staffs of the post-operative settings. The child was found with gradual improvement and recovery of his presenting problem and surgery settings were waiting for biopsy report to their hand.

\section{Histological Findings}

Dr. A. K. M. Nurul Kabir (Associate Professor): The histopathological report of the polypoid lesion demonstrated $\beta$ cell lymphoma of intestinal mucosa and sub-mucosa (x200 H \& E stain) (Figure 4A), intestinal mucosa ( $x 400 \mathrm{H}$ \& E stain ) (Figure 4B). Based on St. Jude's staging system, the child was staged as non-Hodgkin's lymphoma stage II, $\beta$ cell type having a uniform, round to oval nuclei with few vesicular chromatins and one or a significant number of conspicuous nucleoli (x200 H \& E stain ) (Figure 4C) confirmed the diagnosis of the child as diffuse large $\beta$ cell non-Hodgkin's lymphoma. Some of the isolated mesenteric nodes were found as reactive in type. The remaining part of the intestine was found no abnormality.

Dr. Hafiz: The parents were advised to perform a 


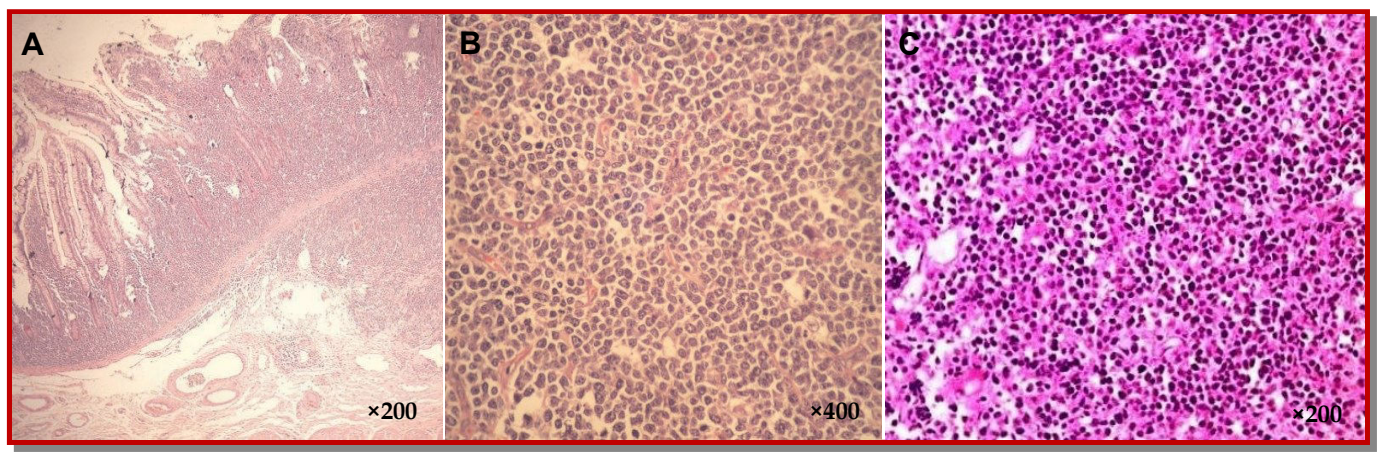

Figure 4: Photograph showing histological examination demonstrating B-cell lymphoma of intestinal mucosa \& submucosa $(\times 200 \mathrm{H} \& \mathrm{E}$ stain) (A); intestinal mucosa (x400) (B); non-Hodgkin's lymphoma of diffuse large B-cell type, uniform, round to oval nuclei with few vesicular chromatin and one or significant number of conspicuous nucleoli (x200) (C)

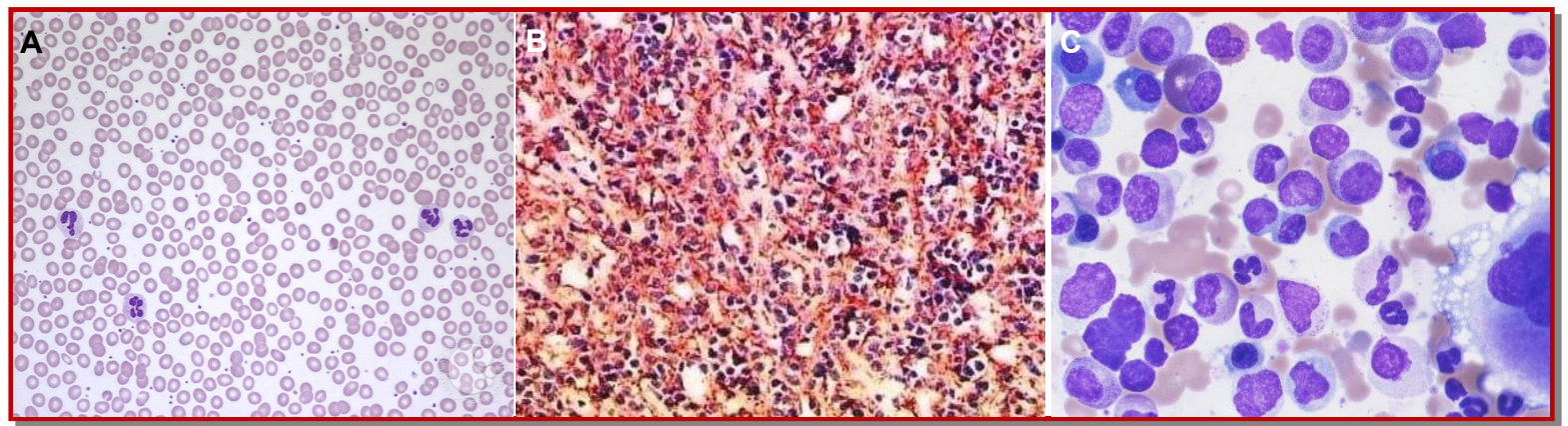

Figure 5: Shows normal peripheral blood findings (A); photomicrograph of cells positive for $\beta$ cell marker (CD20+), immunohistochemical study $(x 200)(B)$; shows normal bone marrow aspiration findings (C)

complete blood count of their child. Then, under all aseptic precautions 2 milliliter of venous blood from antecubital vein was collected in a ethylene diamine tetra-acetic acid (EDTA) tube in the collection room of the laboratory of Pediatric Hematology and Oncology. The slides were appropriately labelled for the identification of patient. The blood slides were prepared by putting a drop of blood from the tube and it was spread by a spreader. The slides were then sent to the laboratory for staining and was stained with Leishman's stain. After proper staining and washing the slides were dried in the room temperature. The slides were observed under light microscope in low power field (x10), high power field ( $x 40 \mathrm{H} \& \mathrm{E}$ stain ) and high power (x100 $\mathrm{H} \& \mathrm{E}$ stain ) to see the hematological parameters. T otal white cell count came back to normal $(10,500$ $\left.x 10^{9} / \mathrm{L}\right)$ along with $55 \%$ neutrophil and other differential count. There was no feature of peripheral relapse in the blood film i.e., no blast cells (Figure 5A).

Dr. Kabir: Following primary management of the acute crisis, the child was transferred from the Department of Pediatric Surgery to the Department of Pediatric Hematology and Oncology for subsequent better management treatment. Thereafter, the tissue block from the operated site was sent to the Department of Pathology for immunohistochemistry study. The report from paraffin-embedded blocks from the supplied tissue confirmed the cells as positive for the marker of $\beta$ cell, CD20+ (Figure 5B).

\section{Bone marrow aspiration findings}

Dr. Chowdhury Yakub Jamal (Professor): When the child completed with all relevant investigations; peripheral blood smear and bone marrow aspiration were done. The bone marrow slides were properly stained with Romanowsky stain in the laboratory of Pediatric Hematology and Oncology. After staining and properly drying the slides were viewed under light microscope. The prepared bone marrow slides were observed in low power $(4 x, 10 x)$, high power (40x H \& E stain) and high power under oil emersion (100x H \& E stain) to see an extension of the disease or metastasis. Examination of the slides under microscope; overall cellularity of the marrow was found normocellular. The myeloid to erythroid ratio was normal. Erythropoiesis was normal and active. Granulopoiesis were found active and orderly. Megakaryocytes revealed normal and active with the evidence of their normal budding. There were the features of tri-lineage hematopoiesis of bone marrow and had no evidence of bone marrow involvement (i.e, $<5 \%$ blast cells). Marrow was not found with parasites or any features of dysplasia (Figure 5C).

\section{Counseling of Parents}

Dr. Hafiz: The parents were well informed about 
the final diagnosis (non-Hodgkin's lymphoma, difuse large $\beta$ cell) of their child. The parents were properly counseled about the nature of the disease, cost, progression of the disease and its outcome. Following proper counseling to the parents and with the normal baseline hematological, biochemical, normal bone marrow aspiration findings, immunohistochemistry report cells positive for $\beta$ cell marker (CD20+). The child had started protocol-based chemotherapy at the Department of Pediatric Hematology and Oncology.

\section{Chemotherapy Schedule}

Dr. Hafiz: The child started chemotherapy with LMB -96 protocol (intermediate risk). The pre-phase and induction, consolidation and maintenance therapy were given. The pre-phase induction (COP) was for 7 days, given with a) vincristine $\left(1 \mathrm{mg} / \mathrm{m}^{2}\right.$ through a new intravenous channel), b) cyclophosphamide $\left(300 \mathrm{mg} / \mathrm{m}^{2} /\right.$ dose intravenously over $30 \mathrm{~min}$ in 100 $\mathrm{mL}$ normal saline), c) intrathecal methotrexate (12 $\mathrm{mg})$ plus hydrocortisone $(25 \mathrm{mg})$ on day 1 and prednisolone $\left(60 \mathrm{mg} / \mathrm{m}^{2}\right)$ twice daily orally after meal from day 1 to day 5 of induction. Thereafter, the dose of prednisolone was tapered. Then, the hematological, biochemical, renal and liver function tests were done prior to starting the induction phase. Induction was given with COPADM-1. Vincristine $\left(2 \mathrm{mg} / \mathrm{m}^{2}\right)$ was given through a new intravenous channel. High dose methotrexate $\left(3 \mathrm{~g} / \mathrm{m}^{2}\right)$ intravenously was administered over 3 hours on day 1 of therapy. The calcium leucovorin $(15 \mathrm{mg} /$ $\mathrm{m}^{2}$ ) was administered intravenously 6 hours for 12 doses until his serum level of methotrexate became $0.1 \mu \mathrm{M} / \mathrm{L}$. The rescue started at 24 hours of the high dose methotrexate. The cyclophosphamide (250 $\mathrm{mg} / \mathrm{m}^{2}$ ) given intravenously from day 2 to day 4 of the therapy. The child was then hydrated with normal saline at $125 \mathrm{~mL} / \mathrm{m}^{2} /$ hour intravenously until the 12th dose. 2-Sodium mercaptoethane sulfonate $400 \mathrm{mg} / \mathrm{m}^{2} /$ dose at $0,6,9,15,18$ and 21 hours for each day was administered to prevent hemorrhagic cystitis. Doxorubicin $\left(60 \mathrm{mg} / \mathrm{m}^{2}\right)$ infusion was given over 6 hours on day 2 following cyclophosphamide. Intrathecal methotrexate was given on day 2 and day 6 . The prednisolone was given orally after meal twice in divided doses from day 1 to day 7 of therapy.

After an interval of 21 days, COPADM-2 protocol of therapy was given successfully without any gross unwanted event. The child was, then, started consolidation phase with CYM-1 protocol with high dose methotrexate $\left(3 \mathrm{~g} / \mathrm{m}^{2}\right)$ intravenously in 3-hour infusion on day 1 of therapy followed by folinic acid rescue $\left(15 \mathrm{mg} / \mathrm{m}^{2}\right)$ intravenously 24 hours of methotrexate therapy of 6 hourly doses for 12 doses until the serum methotrexate level $<0.1 \mu \mathrm{M} / \mathrm{L}$. Then, the child was given intrathecal methotrexate plus hydrocortisone on day 2, intrathecal cytara- bine plus hydrocortisone was also given on day 7 of the therapy. Granulocyte-macrophage-colony-stimulating agent $(300 \mathrm{U} / 0.5 \mathrm{~mL})$ was given intravenously on day 7 of therapy to stimulate the bone marrow cell to regenerate. Then, every two days interval his blood count, liver function and renal function were done to see any deviation from the normal. The same schedule of CYM-2 protocol was given to the child after an interval of 21days. He received all the scheduled chemotherapy protocol in time, but there were some unwanted adverse events happened ( 3 episodes febrile neutropenia and mucositis after COPADM-1, CYM-1, and CYM2 therapy); which was managed successfully with broad-spectrum antibiotics and supportive care).

After completion of the protocol-based chemotherapy, parents were advised to attend their child at the out-patient department for regular follow-up. On follow-up, till now the child exhibits good treatment compliance with a clinical, hematological, biochemical and ultrasonographical parameter having no sign or symptom of relapse for the last two years.

\section{Provisional Diagnosis}

Non-Hodgkin's lymphoma

\section{Differential Diagnosis}

While thinking of the differential diagnosis, it should be considered the age of the child at presentation, site of abdominal pain, mass and passage of loose stool mixed with blood. As there was no abnormality other than the pain and cramp in the abdomen which was progressively increasing in nature with nausea, vomiting, and passage of loose stool mixed with blood; the following differential diagnosis should be bear in mind.

\section{Non-Hodgkin's lymphoma}

Dr. Hafiz: The pediatric population constitutes $32.4 \%$ of the total population of this subcontinent and the malignancies are emerging major childhood killer.1 The primary tumor of the gastrointestinal tract is rare and it is less than $5 \%$ of all childhood malignancies. 2 The scarcity of the disease and early variable clinical presentation preclude early diagnosis when the likelihood of cure exists. Among the gastrointestinal malignancies, non-Hodgkin's lymphoma is the predominant variety. In children, these tumors tend to found in the small and large intestine in contrast to stomach in adults. $\frac{3}{-}$ It is the most frequent cause of intestinal obstruction due to intussusceptions during the first 2 years of life. $\underline{4,5}$ The incidence of intussusceptions is 1.5-4 cases per 1,000 live births, with a male: female ratio $3: 2.6,5$ It often occurs around one year of age with a peak incidence between 4 and 7 months ..-1 In infants 
aged 9-24 months, it is usually primary. They do not have an identifiable specific lead point. A specific lead point is more commonly found in children older than 3 years. 8 Intussusceptions caused by Burkitt's lymphoma ( $\beta$ cell type) as a cause of acute abdomen is rare, which often mislead the symptoms that make the diagnosis more difficult. 9 Many pediatric patients with Burkitt's lymphoma may present with intussusceptions as a first clinical sign, a presentation that potentially leads to the detection of disease at an earlier stage. 10 The commonest variety of intussusceptions is ileocolic.11 In the present situation, this variant of intussusceptions was also common, which matched with their findings.

Another study in Bangladesh by Rahman et al. (2016) 12 , where it is found $38(76 \%)$ patients ileocolic type, 8 ileoileo colic, and 6 ileo ileal type. Swelling of the lymphoid tissue of intestine (the mesenteric lymph nodes and Peyer's patches) is thought to be a lead point for the intussusception after infection or inflammation. $\underline{13}$ In the majority $(89 \%)$ of the patients, thick and edematous ileal wall and enlarged mesenteric lymph nodes are found during operation. The enlarged mesenteric lymph nodes have been suggested to act as a lead point in intussusceptions. They demonstrated that $60-100 \%$ have hypertrophy of the Payer's patches/enlarged lymph nodes. The present case showed ileoileocolic intussusceptions with a small $(2.25 \times 2.25 \mathrm{~cm}) \mathrm{sub}$ -mucosal sessile polyp. The firm inconsistency in the distal ileum as the leading point along with mild to moderate congestion and hemorrhage in the intestinal mucosa.

Though it is uncommon, the primary non-Hodgkin's lymphoma is found to be the initiating point in intussusceptions, commonly involving the terminal ileum. $\underline{.14,15}$ The present case also initiated with the presentation of intussusceptions, which is consistent with the author's findings. The children with Burkitt's lymphoma or non-Hodgkin's lymphoma have an excellent prognosis with contemporary treatment regardless of disease stage. $\frac{10,16}{1 n}$ this case, following protocol-based chemotherapy in the scheduled dose and duration, was found with excellent outcome having no sign and symptom of relapse. It is also consistent with the other author's observations.

However, in this case, though the child initially presented with the features of intussusceptions although there were definite clinical, radiological, histopathological and immunohistochemistry findings which finally confirmed as non-Hodgkin's lymphoma of the small intestine.

\section{Henoch-Schonlein purpura}

Dr. Jamal: Although Henoch- Schonlein purpura can affect the children of any age, most of the cases occur in children between the ages of 2 to 11 years.
Henoch-Schonlein purpura may presents with bleeding per rectum due to thrombocytopenia. 17 In the present case, no typical rash was found in the buttock and extensor surface of hand and foot or arthritis which is typical for the disease but not found in this case.

In contrary, the present case, child complaints of a mass in the abdomen, diffuse abdominal pain, and passage of stool mixed with blood. His per rectal examination presents a jelly-like stool. The plain Xray of the abdomen revealed a dilated loops of bowel with the significant number of air-fluid levels which is against the diagnosis of HenochSchonlein purpura.

\section{Intussusceptions of the small intestine}

Dr. Md. Anwarul Karim (Professor): The 2-year-old child presented with a history of diffuse abdominal pain and mass in the abdomen. On examination, he was mildly pale. Laboratory investigations showed a white blood cell count of $25 \times 10^{9} / \mathrm{L}$ with neutron -philia, i.e., neutrophilic leukocytosis (90\%). Painful distension of abdomen along with the signs of peritonitis were observed on per abdominal examination. His bowel sounds were found to be increased on auscultation The abdominal ultrasonography findings revealed intussusceptions of the bowel at the right lumbar region which extent to the epigastric region with the involvement of lymph nodes of the mesentery. Red currant jelly-like stool and ballooning of the rectum had observed on per rectal examination. So, this can be considered as intussusceptions of the small intestine. Subsequently, the computed tomography scan, histopathology, and immunohistochemistry report from the biopsy sample were against the diagnosis of intussusceptions.

\section{Neutropenic colitis (Typhilitis)}

Dr. Md. Imrul Kaes (MD Resident): It can also occur in association with the diffuse process including neutropenic colitis. $\underline{18}$ Most patients who are affected with neutropenic enterocolitis are receiving antineoplastic drugs and are profoundly neutronpenic (i.e., $<1000$ cells $/ \mu \mathrm{L}$ ). The time course and severity of the clinical presentation of neutropenic enterocolitis are variable. The symptoms usually occur within 10-14 days after the initiation of cytotoxic chemotherapy. In this particular presentation, there was no history of receiving any chemotherapeutic agent earlier to this illness and the hematological parameters were found within the normal limits. So, neutropenic colitis could be excluded.

\section{Shigellosis}

Dr. Niaz Mahmud (MD Resident): This case had the history of passage of blood mixed in the stool, vague abdominal pain, mass in the abdomen and fever. On examination, the child was found mildly 
pale, sweaty with the distended, diffusely tender and painful abdomen. His per rectal examination revealed red currant jelly stool with balloonlike swelling of the rectum. The per-operative findings, computed tomography scan, a histopathological report from a biopsy sample and immunohistochemistry was against the diagnosis of shigellosis.

\section{Disseminated tuberculosis}

Dr. Hafiz: The abdominal tuberculosis is an important global health problem and our country has a high prevalence of tuberculosis which includes both pulmonary and extrapulmonary types. Two separate studies were done in Bangladesh by Islam et al. (2017) $\underline{19}$ and Sultana et al. (2017) $\underline{20}$, where extrapulmonary form of tuberculosis is found to be more common in the younger group of children. The incidence of disseminated tuberculosis ranges from $1-3 \%$ of all tuberculosis cases reported by Dominguez et al. (1991)21 and Ibe et al. (1997).22 The disseminated form of tuberculosis is more common in infant and children. $\underline{23}$ Wang et al. (2007)르 reported the definition of disseminated tuberculosis as tuberculous infection involving the bloodstream, bone marrow, liver or involvement of two or more non-contiguous sites, or miliary tuberculosis.

Dr. Afiqul Islam (Professor): Although the child presented with diffuse abdominal pain, the mass within the abdomen and passage of red currant jelly stool. On examination, the baby was found immunized as per expanded program on immunization schedule and had no history of contact with tuberculous patients or any prolonged cough, having normal erythrocyte sedimentation rate and chest X-ray findings. So, the tuberculosis is fewer possibility in this case. On the contrary, histopathology, immunohistochemistry and CT scan report did not match with disseminated tuberculosis.

\section{Dr. Jamal's Diagnosis}

Non-Hodgkin's lymphoma of the small intestine

\section{Discussion}

Dr. Hafiz: Julie and Bernard (2002)1ㅡ reported that $54 \%$ patients had the history of recent gastroenteritis, while $40 \%$ had the history of respiratory tract infection. WHO in 2002 showed over 40\% patients from Chandigarh of India in March or April found the history of viral gastroenteritis and nearly $45 \%$ found upper respiratory tract infection. In this situation, there was no such type of correlations. Non-Hodgkin's lymphoma of the gastrointestinal tract is the most common variant of extranodal lymphoma. $\underline{25}$ The small and large intestines are the most common involving site, $\underline{25}$ the most common site is ileum where most of the gut is surrounded by lots of lymph nodes. These lymph nodes are commonly arise from the $\beta$ cells of lymphoid tissue which exist in the lamina propria and submucosa of the intestine. These may be solitary or diffuse. The solitary type tends to encircle the whole of bowel and so that it narrows the entire lumen and the diffuse variants are found with multi-segment involvement with numerous polypoidal excrescences which may finally invade the serosal layer up to the mesentery or its beyond.

Meckel's diverticulum has been found to be the most common leading point of intussusceptions. In the small intestine, intussusception can be secondary to the presence of intra- or extraluminal lesions, i.e, inflammatory Meckel's diverticulum, post-operative adhesions, lipoma, adenomatous polyp, lymphoma and metastases and there may be iatrogenic presence intestinal tubles. 8, 14-15, 26-28 Other reported leading points are polyps, duplication cyst, carcinoid, leiomyoma, hemangioma, fibrosarcoma and buried appendicectomy stump which retain after surgery. $14,15,27, \mathrm{~T}$ h is can also found in association with a diffuse process including Henoch-Schonlein purpura, celiac disease, neutropenic colitis, cystic fibrosis, and Peutz Jehgers syndrome. $\underline{29-31}$ The incidence of nonHodgkin's lymphoma acts as a lead point of intussusceptions is reported as high as $17 \%$ and even higher (more than 50\%) in children over 4-6 years of age. $\frac{8,26,28}{}$ In the Western population, $60 \%$ to $80 \%$ of intestinal lymphomas have been reported to be the B-cell lymphomas which are mostly diffuse large Bcell lymphoma of the distal small intestine. $\underline{32,33}$ It is found that the case is diagnosed as diffuse large $\beta$ cell lymphoma which is consistent with the findings of the previous authors.

There was a sessile polyp in the distal ileum and the child went home after a right hemicolectomy followed by protocol-based chemotherapy with cyclophosphamide, adriamycin, vincristine, prednisolone, and methotrexate in schedule dose and duration and on regular follow-up at the out-patient department. The child exhibited good treatment compliance till now.

It is observed in the present case who survived till now without any event which was against the observation of Ein et al. (1986)르 where only 3 patients out of 10 were long-term survivors. Puri and Guiney (1985) $\underline{15}$ also reported that the only one death out of 292 children with intussusceptions in a child with lymphoma. Lymphoma is the most common type malignant lesion of the small bowel in children. $\underline{15}$ Hence, in cases of intussusceptions, especially in the older age group of the children, we need to keep a high index of suspicion for malignant lymphoma of the bowel when they present with vague abdominal 
pain, mass in the abdomen and red currant jelly stool. The importance of resection of bowel containing any slightest lesion along with the removal of the regional lymph nodes is stressed. With these reports, it is tried to highlight the differing presentations of non-Hodgkin's lymphoma and the differing unpredictable outcomes. In this particular case, it is found with an excellent prognosis after diagnosis and following treatment. La Quaglia et al. (1992)32 concluded that bowel resection performed during emergency laparotomies for symptomatic, localized bowel involvement in patient with nonHodgkin's lymphoma was associated with better prognosis. These findings are also consistent with the observations of authors. Intestinal involvement by non-Hodgkin's lymphoma was associated with an increased frequency of abdominal symptoms resulting in earlier laparotomies and earlier diagnosis.

A mesenteric or retroperitoneal mass that does not involve the bowel wall remains clinically silent until a relatively larger tumor burden is reached. Complete resection of the tumor was shown to have the added advantage of avoiding bowel perforation, gastro-intestinal hemorrhage or the tumor lysis syndrome after the initiation of chemotherapy. $\underline{.34-36}$ It is reported that non-Hodgkin's lymphoma involving the bowel, surgical resection has been associated with the improved outcome by complete resection in localized disease confined to the bowel wall and diagnostic biopsy in advanced diseases. $\underline{37}$ As this index case was localized and had no sign of distance metastasis, our finding was consistent with others. Hence, with high suspicion of lesions, considering the age of the child and the bowel involvement, resection of the diseased bowel may be the single most important dicision in salvaging these children.

The role of debulking has been condemned in extensive abdominal tumors which are associated with complication and possible delay in initiation of essential systemic chemotherapy. .55 In our perspective, there was no such complication but had gradual improvement. The extent of disease at presentation and the resectability has been found to be the most important prognostic factor. 32,37 Our index case also had found with ileoileocolic intussusceptions with a small submucosal sessile polyp; firm inconsistency in the distal ileum as the leading point along with mild congestion and hemorrhage in the mucosa.

It is reported by Haas et al. (2003) 38 that about 30\% cases of malignancy are found in the intestine and Martin et al. (2004) 39 also observed about $66 \%$ of the malignancy that originates in the large intestine. In the present situation, the site of origin of the tumor is a small intestine.
So, that the pediatric surgeon/physician should bear in mind about non-Hodgkin's lymphoma when a child present with a non-specific clinical presentation like diffuse abdominal pain, a mass in the abdomen and red currant jelly stool so that it can give a clue to do the further diagnostic evaluation.

\section{Final Diagnosis \\ Non-Hodgkin's lymphoma, diffuse large $\beta$-cell}

\section{Follow-up}

Dr. Hafiz: Non-Hodgkin's lymphoma results from malignant multiplication of the lymphoid lineage of a cell. Although malignant lymphomas are generally uncommon to lymphoid tissue such as lymph node, Peyer's patches of small intestine and spleen, it is not uncommon to find bone marrow involvement in children. Furthermore, as it is mandatory to provide a multidisciplinary approach of chemotherapy which results in immunosuppression of the patient. So, the child needs good personal health and immunocompetent enough to cope up from these unwanted adverse effects of the drugs.

Dr. Hossain: How would you follow-up the child?

Dr. Hafiz: Following hemicolectomy, protocolbased chemotherapy had given to the child with regular follow-up for the last 24 months and till now the child did not develop any sign and symptom of the reappearance of the disease. He was done a monthly follow-up with complete blood count and biochemical parameters (serum lactate dehydrogenase) to see any deviation from the normal. To exclude metastasis/relapse, ultrasonogram and bone marrow aspiration were done every 6-months interval. Till now, the child clinical, hematological or ultrasonographically exhibits good treatment compliance without any sign and symptom of relapse.

\section{Future Suggestion}

Dr. Kabir: What is the take-home message?

Dr. Hafiz: Any children below 6 years of age when present with intermittent abdominal pain, vomiting, mass in the abdomen/abdominal distention and bloody stool, they must be excluded for nonHodgkin's lymphoma. The children with high index suspicion for malignant lymphoma of bowel with the concomitant presentation of intussusceptions, a physician/surgeon should be aware to perform computed tomography scan of the abdomen, histopathological examination of the tissue sample, immunohistochemistry and bone marrow aspiration for diagnosing and staging of 
lymphoma for the subsequent management.

\section{Ethical Issue}

Informed written consent was taken from the parents. The confidentiality, privacy, respect, and responsibility of the patients have followed the method of World Medical Association Declaration of Helsinki, 2000.

\section{Conflict of Interest}

The authors did not have any conflicts of interest regarding the publication of the paper.

\section{Acknowledgements}

We express our sincere thanks to the related staffs of the Department of Pediatric Surgery, Bangabandhu Sheikh Mujib Medical for their cordial help in taking photograph during operation. We must also give thanks to concerned staffs of the Department of Pathology, BSMMU for preparing histopathology and immunohistochemistry report.

\section{References}

1. Pattnaik N, Khan MA, Rao ES, Rao BRM. Pediatric malignancies. J Clin Diagn Res. 2012; 6: 674-77.

2. Bandyopadhyay R, Sinha SK, Chatterjee U, Nag D, Mukhopadhyay S, Chowdhury SR, Biswas PK. Primary pediatric gastrointestinal lymphoma. Indian J Med Pediatr Oncol. 2011; 32: 92-95.

3. Kassira N, Pedroso FE, Cheung MC, Koniaris LG, Sola JE. Primary gastrointestinal tract lymphoma in the pediatric patient: Review of 265 patients from the SEER registry. J Pediatr Surg. 2011; 46: 1956-64.

4. Gupte S. Pediatric surgery. In: The short textbook of pediatrics. 9th ed. New Delhi, Jaypee Brothers Medical Publishers (P) Ltd., 2001, pp 604-14.

5. Di Fiore JW. Intussusceptions. Semin Pediatr Surg. 1999; 8: 214-20.

6. Simpson T, Ivey J, Borkowski S. Pediatric management problems: Intussusceptions. Pediatr Nursing. 2004; 30: 326-27.

7. Fischer TK, Bihrmann K, Perch M, Koch A, Wohlfahrt J, Kare M, Melbye M. Intussusceptions' in early childhood: A cohort study of 1.7 million child ren. Pediatrics 2004; 114: 782-85.

8. Ong NT, Beasley SW. The lead point in intussusceptions. J Pediatr Surg. 1990; 25: 640-43.

9. Hoxha TF, Hashani SI, Krasniqi AS, Kurshumliu F, Komoni DS, Hasimja SM, Maxhuni M. Intussusceptions as acute abdomen caused by Burkitt lymphoma: A case report. Cases J. 2009; 2: 9322.
10. Gupta H, Davidoff AM, Pui CH, Stephen J, Shochat, Sandlund JT. Clinical implications and surgical management of intussusceptions in pediatric patients with Burkitt lymphoma. J Pediatric Sur. 2007; 42: 998-1001.

11. Julie EB, Bernard I. Acute intussusception in infants and children incidence, clinical presentation, and management: A global perspective. WHO/ V\&B. 2002; 19: 34.

12. Rahman M, Islam MT, Rahman H, Ahmed M. Etiological factors of intussusception among children in a tertiary care hospital. Bangladesh Med J Khulna. 2016; 49: 23-26.

13. Sigmound EH, Daneman A. Intussusception. In: Pediatric surgery. Grosfeld JL, O'Neill JA, Arnold G C, Fonkalsrud EW (eds). Philadelphia, Mosby, 2006; pp 1313-41.

14. Ein SH. Leading points in childhood intussusceptions. J Pediatr Surg. 1976; 11: 209-11.

15. Puri P, Guiney EJ. Small bowel tumors causing intussusceptions in childhood. Br J Surg. 1985; 72: 493-94.

16. Chieng JHC, Garrett J, Ding SL, Sullivan M. Clinical presentation and endoscopic features of primary gastric Burkitt lymphoma in childhood, was presented as a protein-losing enteropathy: A case report. J Med Case Rep. 2009; 3: 7256.

17. Grosfeld J. Intussusceptions then and now. J Am Coll Surg. 2005; 201: 830-33.

18. Daneman A, Alton DJ, Lobo E, Gravett J, Kim P, Ein SH. Patterns of recurrence of intussusceptions in children: A 17-year review. Pediatr Radiol. 1998, 28: 913-19.

19. Islam Z, Sanin KI, Ahmed T. Improving case detection of tuberculosis among children in Bangladesh: Lessons learned through implementation research. BMC Public Health. 2017; 17: 131.

20. Sultana AT, Gathia R, Huda MM, Begum JA, Kamruzzaman, Amin MR. The pattern of childhood tuberculosis among the patients admitted in Dhaka Shishu (Children) Hospital. Northern Int Med Coll J. 2017; 8: 213-15.

21. Dominguez FP, Cenarro GT, Rivas CA, Rituerto GB, Franco LY, de Juan MF. Tuberculosis: Epidemiologic and clinical study of 268 pediatric patients. An Esp Pediatr. 1991; 35; 26-30.

22. Ibe M, Mori M, Mitsuda T, Aihara Y, Yokota S. Analysis of children with tuberculosis in the past 20 years. Kansenshogaku Zasshi. 1997; 71: 513-21.

23. Sharma SK, Mohan A, Sharma A. Milliary tuberculosis: A new look at an old foe. J Clin Tuber Other Mycobact Dis. 2016; 3: 13-27.

24. Wang JY, Hsueh PR, Wang SK, Jan IS, Lee LN, Liaw YS, Yang PC, Luh KT. Disseminated tuberculosis: A 10-year experience in a medical center. Medicine 2007: 86: 39-46. 
25. Ford EG. Gastrointestinal tumors. In: Pediatric surgical oncology. Andrassy RJ (ed). 1st ed. Philadelphia, WB Saunders, 1998, pp 289-304.

26. Wayne ER, Campbell JB, Kosloske AM, Burrington JD. Intussusceptions in the older child-suspect lymphosarcoma. J Pediatr Surg. 1976; 11: 78994.

27. Eisen LK, Cunningham JD, Aufses AH Jr. Intussusception in adults: An institutional review. J Am Coll Surg. 1999; 188: 390-95.

28. Ein SH, Stephens CA, Shandling B, Filler RM. Intussusceptions due to lymphoma. J Pediatr Sur. 1986; 21: 786-88.

29. Navarro O, Dugougeat F, Korecki A, Shuckett B, Alton DJ, Daneman A. The impact of imaging in the management of intussusceptions owing to pathologic lead points in children: A review of 43 cases. Pediatr Radio. 2000; 30: 594603.

30. Daneman A, Alton DJ, Lobo E, Gravett J, Kim P, Ein $\mathrm{SH}$. Patterns of recurrence of intussusceptions in children: A 17-year review. Pediatr Radiol. 1998, 28: 913-19.

31. Grosfeld J. Intussusceptions then and now. J Am Coll Surg. 2005; 201: 830-33.

32. LaQuaglia MP, Stolar CJH, Krailo M, Siegel S, Meadows A, Hammond D. The role of surgery in abdominal non-Hodgkin's lymphoma: Experi- ence from the children cancer study group. J Pediatr Surg. 1992; 27: 230-35.

33. Domizio P, Owen R, Shepherd NA, Talbot IC, Norton AJ. Primary lymphoma of the small intestine: A clinicopathological study of 119 cases. Am J Surg Pathol. 1993; 17: 429-42.

34. Janus C, Edwards BK, Sariban E, Magrath IT. Surgical resection and limited chemotherapy for abdominal undifferentiated lymphomas. Cancer Treat Rep. 1984; 68: 599-605.

35. Cohen LF, Balow JE, Magrath IT. Acute tumor lysis syndrome: A review of 37 patients with Burkitt's lymphoma. Am J Med. 1980; 68: 486-91.

36. Meyers PA, Potter VP, Wollner N, Exelby P. Bowel perforation during initial treatment for childhood non-Hodgkin's lymphoma. Cancer 1985; 56: 25961.

37. Fleming ID, Turk PS, Murphy SB, Crist WM, Santana VM, Rao BN. The surgical implication of primary gastrointestinal lymphoma of childhood. Arch Surg. 1990; 125: 252-56.

38. Haas EM, Etter EL, Ellis S, Taylor TV. Adult intussusception. Am J Surg. 2003; 186: 75-76.

39. Martin LJG, Torralba MA, Liron RR, Flores PB, Miguel PJ, Aguilar JJ, Aguayo AJL. Intestinal invagination in adults: Preoperative diagnosis and management. Int J Colorectal Dis. 2004; 19: 68-72. 